\title{
Adaptation and validation of the Euthanasia Attitude Scale into Spanish
}

2020, Vol. 27(5) $120 \mid-1212$

(C) The Author(s) 2019

Article reuse guidelines:

sagepub.com/journals-permissions

I0.1177/0969733019864162

journals.sagepub.com/home/nej

@SAGE

\section{María Dolores Onieva-Zafra}

University of Castilla-La Mancha, Spain

Juan José Fernández-Muñoz $\mathbb{B}$

Universidad Rey Juan Carlos, Spain

\section{María Laura Parra-Fernandez $\mathbb{\oplus}$, Cristina Romero-Blanco and Elia Fernández-Martínez}

University of Castilla-La Mancha, Spain

\begin{abstract}
Background: Considering the extensive debate that is currently taking place in Spain regarding euthanasia, it is important to examine the attitude of professionals who perform most of their duties at the bedside of these patients and their families.

Objectives: The aim of the present study was to present an adaptation and validation of the Euthanasia Attitude Scale and to evaluate its psychometric properties among a sample of nursing students in Spain.

Research design: A cross-sectional study design was conducted.

Participants and research context: Non-probabilistic sampling was used to recruit 396 Spanish nursing students.

Methods: A self-report questionnaire, including socio-demographic data and the Euthanasia Attitude Scale, were used for data collection. The psychometric properties of the Euthanasia Attitude Scale were assessed, including reliability and validity. Fit indices of the overall model were computed.

Ethical considerations: This study was approved by the Hospital Ethical Committee. Students were informed of the aims and procedures and provided written informed consent prior to data collection.

Results: The factorial solution comprised four domains and the scale demonstrated adequate internal consistency (Cronbach's alpha $=.878$ ). For the exploratory factor analysis, the Kaiser-Meyer-Olkin index of sampling adequacy was .905 and the Bartlett's Test of Sphericity was $2972.79(p<.001)$. The initial factorial solution revealed four factors with eigenvalues of 6.78 for the first factor, 1.90 for the second one, 1.29 for the third, and I.I 0 for the fourth factor. Moreover, there was a significant relationship between religiosity and the domains of the Euthanasia Attitude Scale.

Discussion: This study obtained a Cronbach's alpha coefficient of .88 which is in consonance with the findings reported by other studies whereby none of the items were removed and the initial structure based on four domains was conserved, with a factorial solution that explains $52.79 \%$ of the total variance. The
\end{abstract}

Corresponding author: María Laura Parra-Fernandez, Faculty of Nursing, University of Castilla-La Mancha, Ciudad Real, I3007 Spain.

Email: marialaura.parra@uclm.es 
displacement of some items of the domain may be explained by certain religious and/or cultural components as, in accordance with other studies, people with firm religious beliefs are more inclined to refuse euthanasia.

Conclusion: According to the findings of this study, the Euthanasia Attitude Scale is a reliable and valid instrument to measure the attitudes toward euthanasia in a sample of Spanish nursing students. This Spanish adaptation will be valuable in future studies examining the attitude and implication of nurses, understanding that nurses are key figures in the euthanasia debate.

\section{Keywords}

Clinical ethics, euthanasia, instrument validation, professional ethics, psychometric properties, religiosity

\section{Introduction}

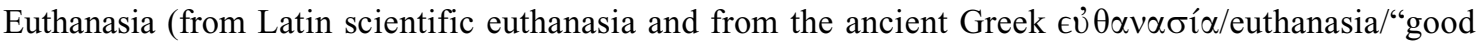
death") refers to a voluntary, intentional, studied, and conscious procedure performed by a physician to hasten the death of a terminally ill patient. ${ }^{1}$ This decision is reached due to the conscious, studied, and deliberate request of the patient or relatives who, being fully aware that there is no curative treatment available for the specific disease, request the physician to perform euthanasia on the patient in order to end their intolerable and intractable pain and suffering. ${ }^{2}$ In popular terms, for those in favor of euthanasia, "sweet death" would be a correct way to define the same, while those against euthanasia tend to use terms, such as "homicide."

In recent years, the controversy surrounding euthanasia has been a constant topic of debate among politicians, sociologists, and healthcare professionals. Indeed, the legalization of euthanasia continues at the forefront of political debate in many countries. ${ }^{3}$ The outcome of any potential new legislation will undoubtedly have much to do with society's opinion regarding this issue.4 Several cases have gained the attention of the international media, highlighting the growing interest of the population regarding an issue which, undoubtedly will continue to be at the forefront of public opinion, as both the active aging of the population as well as current medical advances highlight the fact that citizens are pondering end-of-life issues, considering that death must be accepted as a part of life. ${ }^{5}$ Several international studies suggest a tendency for public opinion to be more favorable for euthanasia than, for example, doctors, or other health professionals, for which there is a lack of studies examining professional opinion. ${ }^{1}$ The last survey performed in 2008 in 47 European countries revealed relatively high results regarding the acceptance of euthanasia in countries such as Denmark, Belgium, France, The Netherlands, Sweden, and Spain. ${ }^{4}$ It is surprising that, compared to the survey published in the year 2000, Spain has gone from position 19 in this ranking to position 6, alongside countries such as Germany, Great Britain, Portugal, or Italy, which have also risen through this ranking despite being countries where euthanasia is not permitted by law. ${ }^{6}$ In another study performed with health professionals in six European countries, family members and patients of three different religions, there was no difference between the three religions regarding euthanasia. However, the importance of being religious versus just being affiliated to (being a member of) a religion was highlighted. Religious respondents required more treatment and were more in favor of life prolongation; however, respect for patient autonomy was apparently more a question of background and culture than a question of religion. $^{7}$ These findings are in contrast to a study performed in the United States involving primary care doctors, where the level of religiosity did have an impact on the principle of patient autonomy. ${ }^{8}$ 
Spain is a secular country and, despite the fact that Catholicism has been losing ground in the public sphere, the Catholic religion has been and continues to be deeply rooted in the culture, interacting with many national traditions. Likewise, Spain also recognizes the right to conscientious objection when health professionals face specific practices that go against their principles, values, or beliefs. In this sense, the freedom to act according to their principles does not violate the right to decision at the end of the life of the patient. ${ }^{9}$ However, some studies show that the influence of religious beliefs regarding conscientious objections tend to consider that the health professional's right to the same becomes more important than the patients' healthcare rights. ${ }^{10,11}$

Research on attitudes toward euthanasia have been conducted in many countries. ${ }^{12-19}$ However, the way in which nurses perceive euthanasia or even the possibility of these professionals participating in this process is currently a silent or hushed debate taking place in many hospitals and nursing homes, in which the nurse provides care and spiritual support to dying patients and their families. A recent study conducted in Belgium reported that $99 \%$ of nurses surveyed indicated that the management of euthanasia requests and other topics related with end of life should be a part of nurses' formal education. ${ }^{17}$ In Finland, the study by Terkamo-Moisio et al.14 revealed that most nurses felt that their opinion should be considered in decision-making processes regarding euthanasia. Furthermore, $74.7 \%$ of participants declared that they would be willing to participate in the euthanasia process if this were legal. In France, the study by Bendiane et al. ${ }^{20}$ reported that $48 \%$ of the nurses surveyed supported the legalization of euthanasia. In a previous study by the same author with a sample of 600 nurses, $65 \%$ agreed to the legalization of euthanasia; however, the female nurses, and among these, those of an older age were most reluctant to support euthanasia, influenced by their marked religious profession. In New Zealand, while only $37 \%$ of doctors supported legalizing Assisted Dying, $67 \%$ of nurses were supportive. ${ }^{21}$ In countries with extensive experience in implementing euthanasia practice, the importance of the nurses' role in assisted-dying procedures means that their attitude toward the same cannot be overlooked. ${ }^{14,22}$ In Belgium, a study performed with over 500 nurses, most declare that doctors should discuss the decision of applying euthanasia with nurses who especially are in charge of continuous care. ${ }^{23}$ To our knowledge, and according to the databases consulted, only one study on this topic has been conducted in Spain. This was carried out in Andalusia in 2010, via an ad hoc questionnaire, with the aim of examining the knowledge and attitude of nurses working within the Andalusian health service in the areas of primary and specialized care. ${ }^{24}$

In Spain, euthanasia is banned according to the current legislative framework. This is unlike other European countries, such as Belgium, Holland, and Luxembourg, where euthanasia is legalized. However, since 2010, there is a Law on dignified death which different Spanish communities have embraced, which guarantees citizens with access to pain treatments, while prohibiting therapeutic obstinacy. Therefore, patients may refuse certain treatments although these entail the end of their life. However, Article 143 of the Spanish Criminal Code (Organic Law 10/1995) states four legal provisions regarding legal sanctions (ranging from 6 to 10 years of imprisonment) established on the basis of assumed instigation, cooperation, or causing the assisted suicide/death of another person. The fourth provision of Article 143 contemplates the reduction of the sentence by two degrees in the case of an express, serious, and unequivocal request by the victim suffering from a serious, terminal illness or one that causes serious, permanent ailments that are difficult to endure (as stipulated in the Criminal Code). At present, several groups have begun lobbying for the legalization of euthanasia, such as, for example, the association "Derecho a morir dignamente" (The Right to Die with Dignity - DMD), claiming that there has been an incomplete debate regarding this issue. In accordance, the Chamber of the Spanish Congress of Deputies has encouraged bids for an in-depth debate regarding the social, political, and health issues surrounding euthanasia; a move which would have been unthinkable a few years ago. 
The aim of the present study was to present an adaptation and validation of the Euthanasia Attitude Scale (EAS) and to evaluate its psychometric properties among a sample of nursing students in Spain.

\section{Methods}

\section{Participants}

A non-probability convenience sample of 470 nursing students from a single nursing faculty at the University of Castilla-La Mancha were invited to participate in this study. A total of 396 nurses (70\%) agreed to complete the questionnaire from years 1 to 3 . A prior sample size calculation was not performed, rather the sample size was based on the entire population of students. The inclusion criteria for this study was being a student nurse in this faculty at the time of study. The exclusion criteria consisted of those students who were not willing to participate. All participants provided informed consent prior to participation. Data were collected between September and December 2018. Each student was given a unique identification number, and no names or any identifying personal information was recorded.

\section{Instruments}

The EAS was originally developed and validated by Tordella and Neutens ${ }^{25}$ in 1979 in the United States, to assess the attitude toward euthanasia among college students. Later, this scale was modified by Rogers $^{26}$ in 1996, also in the United States, to assess social values and ethical judgments regarding euthanasia. In 2004, Chong and Fok ${ }^{27}$ performed a study based in Hong Kong and introduced a new modification whereby, after performing a factor analysis, items were grouped into four domains, namely, Ethical Considerations, Practical Considerations, Treasuring Life, and Naturalistic Beliefs. Moreover, in this modified version, the response options were changed from a dichotomous response to a 5-point Likert-type scale, ranging from strongly agree to agree, neutral, disagree, and strongly disagree. The EAS is a scale consisting of 21 items with four domains: ethical considerations ( 11 items), practical considerations (four items), treasuring life (four items), and naturalistic beliefs (two items). The responses were scored based on a 5 -point Likert-type scale where $5=$ strongly agree, $4=$ agree, $3=$ neither agree nor disagree, $2=$ disagree, and $1=$ strongly disagree. The score range was from 21 to 105 , with higher scores representing more positive attitudes to euthanasia. Some examples of items were "a person with a terminal illness has the right to decide to die" (ethical considerations), "euthanasia is acceptable if the person is old" (practical consideration), "there are very few cases when euthanasia is acceptable" (treasuring life), and "a person should not be kept alive by machines" (naturalistic beliefs). The scores of several items were reversed: $1 \mathrm{~b}, 1 \mathrm{~d}, 1 \mathrm{~g}$, and $1 \mathrm{i}$ for the first original factor; $2 \mathrm{c}$ for the second factor; $3 \mathrm{a}$ and $3 \mathrm{c}$ for the third domain; and $4 \mathrm{~b}$ for the fourth. For this study, items $3 \mathrm{~b}$ and $3 \mathrm{~d}$ were also reversed. The original internal consistency index was .84 .

The Attitude toward Euthanasia scale (ATE) ${ }^{28}$ is a measurement tool for attitude toward euthanasia comprising 10 items. The original internal consistency index was .87 . The answers are rated on a 5-point Likert-type scale ranging from 1 to 5 where $5=$ strong support to euthanasia, $3=$ neutral, and $1=$ strong opposition to euthanasia. Some examples of these items are "if a patient in severe pain requests it, a doctor should remove life support and allow that patient to die" or "it is okay for a doctor to administer sufficient medication to a suffering patient to end that patient's life if the doctor thinks that the patient's pain is too severe."

Demographic variables were included in the socio-demographic-questionnaire, such as sex, age, marital status, current course, and religiosity (in order to determine religiosity, a dichotomous question was used, that is, "do you profess any religion?). 


\section{Procedure}

The present study was conducted according to the following two steps: (1) cross-cultural translation and adaptation of the EAS into Spanish and (2) a psychometric assessment of the validity and reliability of the Spanish version of the EAS. The development of the preliminary version of the scale followed the usual recommendations. ${ }^{29}$ Two translations of the original version were made in the corresponding language of the target population on behalf of bilingual translators whose mother tongue was Spanish. A backtranslation of the same was then performed by professionals whose mother tongue was English. Subsequently, the research panel reviewed the translated version, and a second panel, consisting of experienced nurses, reviewed this in order to obtain a semantic and technical equivalence. A pilot study of the final draft was performed with eight Spanish-speaking participants who were students of the nursing faculty in order to assess the comprehension and suitability of the questionnaire and review the fluency, readability, and comprehensibility of items. No major difficulties were reported by the student nurses. This resulted in the final version of the EAS-ES questionnaire.

\section{Data analysis}

Statistical analyses were applied using SPSS 24.0 and R project statistical software. ${ }^{30}$ Assumptions were checked to ensure the application of exploratory factor analysis (EFA), such as multivariate normality, linearity, and a large sample size. ${ }^{31}$ The Kaiser-Meyer-Olkin (KMO) test and tests of sphericity were also calculated to test the adequacy of the data. In order to identify the number of factors, we considered several criteria: eigenvalue greater than 1, scree plot and Horn's parallel test with FACTOR v. 10.3.01. ${ }^{32,33}$ The method of extraction was maximum likelihood and varimax rotation. The internal consistency was checked through Cronbach's alpha and item of homogeneity. Moreover, the ATE was included in this study in order to verify its criterion validity.

\section{Ethical considerations}

Ethical approval for this study was obtained from the Ethics Committee of the University Hospital of Castilla-La Mancha, according to the ethical guidelines established by the Helsinki Declaration in 2008 (Code number C-153). All participants were informed about the project and provided informed consent by completing and submitting all the questionnaires. The students were informed that participation in the study was voluntary. They were also told that their answers would be anonymous and confidential and would not be used for any other purpose than this study.

\section{Results}

Of the 396 participating Spanish nursing students, $80.8 \%$ were female and $19.2 \%$ male. The mean age of participants was $20.18(\mathrm{SD}=3.21)$ with an age range of $18-48$. Regarding their academic studies, $30.3 \%$ were first-year students, $27.3 \%$ were second-year students, $27.5 \%$ were third-year students, and $14.9 \%$ were in their fourth year. Furthermore, 55.8\% professed a religious affiliation while the remaining students had no formal religious affiliation $(44.2 \%)$.

Table 1 describes the means, standard deviations, item homogeneity, and $\alpha$ if item is deleted. In this sense, the homogeneity index was between .116 and .684. There were two items with low item total correlation scores: item 17, "Euthanasia should be practiced only to eliminate physical pain and not emotional pain" and item 21, "Natural death is a cure for suffering." The reliability for the total EAS scores (Cronbach's alpha) was .878. 
Table I. Means, standard deviations, item homogeneity, and $\alpha$ if item is deleted of the Euthanasia Attitude Scale.

\begin{tabular}{|c|c|c|c|c|}
\hline & M & SD & $\begin{array}{l}\text { Item-total } \\
\text { correlation }\end{array}$ & $\begin{array}{l}\text { Cronbach's alpha } \\
\text { if item deleted }\end{array}$ \\
\hline Ia. A person with a terminal illness has the right to decide to die & 4.19 & 0.901 & .641 & .868 \\
\hline lb. Inducing death for merciful reason is wrong & 2.94 & 1.12 & .266 & .879 \\
\hline Ic. Euthanasia should be accepted in today's society & 3.96 & 1.00 & .731 & .864 \\
\hline Id. There are never cases when euthanasia is appropriate & 3.96 & 0.952 & .543 & .870 \\
\hline le. Euthanasia is helpful at the right time and place & 3.96 & 0.948 & .629 & .868 \\
\hline If. Euthanasia is a human act & 3.45 & 1.08 & .684 & .865 \\
\hline Ig. Euthanasia should be against the law & 4.07 & 0.929 & .533 & .871 \\
\hline Ih. Euthanasia should be used when the person has a terminal illness & 3.49 & 1.03 & .416 & .874 \\
\hline li. The taking of human life is wrong no matter what the circumstances & 3.31 & 1.20 & .564 & .869 \\
\hline Ij. Euthanasia is acceptable in cases when all hope of recovery is gone & 3.56 & 1.01 & .609 & .868 \\
\hline Ik. Euthanasia gives a person a chance to die with dignity & 3.61 & 1.18 & .682 & .865 \\
\hline 2a. Euthanasia is acceptable if the person is old & 2.53 & 1.06 & .356 & .876 \\
\hline $\begin{array}{l}\text { 2b. If a terminally ill or injured person is increasingly concerned about the } \\
\text { burden that his or her deterioration of health has placed on his or her } \\
\text { family, I will support his or her request for euthanasia }\end{array}$ & 3.15 & 1.08 & .507 & .871 \\
\hline 2c. Euthanasia will lead to abuses & 3.14 & 1.03 & .322 & .877 \\
\hline $\begin{array}{l}\text { 2d. I have faith in the local medical system to implement euthanasia } \\
\text { properly }\end{array}$ & 3.59 & 0.984 & .468 & .873 \\
\hline 3a. There are very few cases when euthanasia is acceptable & 3.05 & 1.07 & .485 & .872 \\
\hline $\begin{array}{l}\text { 3b. Euthanasia should be practiced only to eliminate physical pain and not } \\
\text { emotional pain }\end{array}$ & 3.35 & 1.07 & .136 & .883 \\
\hline 3c. One's job is to sustain and preserve life, not to end it & 2.78 & 1.17 & .610 & .868 \\
\hline $\begin{array}{l}\text { 3d. One of the key professional ethics of physicians is to prolong lives, } \\
\text { not to end lives }\end{array}$ & 2.70 & 1.17 & .539 & .870 \\
\hline 4a. A person should not be kept alive by machines & 2.79 & 1.11 & .158 & .883 \\
\hline 4b. Natural death is a cure for suffering & 2.85 & 1.05 & .116 & .883 \\
\hline
\end{tabular}

SD: standard deviation.

\section{Construct validity}

For the EFA, the KMO index of sampling adequacy was .905 and the Bartlett's Test of Sphericity was $2972.79(\mathrm{p}<.001)$. The initial factorial solution revealed four factors with eigenvalue values of 6.78 for the first factor, 1.90 for the second one, 1.29 for the third, and 1.10 for the fourth factor. This factorial solution explains $52.79 \%$ of the total variance. Table 2 shows the factor loadings for the factorial solution of four domains. For the first domain, the factorial loading was between 478 and .798; the second domains showed factor loadings between .461 and .750 ; the third domains between -.450 and .754 ; and finally, the fourth factor showed weights of between .468 and .626 .

As displayed in Table 3, total EAS and the dimensions "ethical consideration," "treasuring life," and "naturalistic beliefs" were significantly correlated with total ATE (Spearman $\rho=.391-.564, \mathrm{p}<.001$ ) and also practical considerations (Spearman $\rho=.129, \mathrm{p}<.005$ ). The main diagonal shows internal consistency for each dimension based on Cronbach's alpha.

Finally, Table 4 shows the relationship between the dimension of the EAS and religiosity. In this sense, there were significant correlations between religiosity (professing a religion or not) and ethical considerations $(\mathrm{t}=5.29, \mathrm{p}<.001)$, treasuring life $(\mathrm{t}=4.92, \mathrm{p}<.001)$, naturalistic beliefs $(\mathrm{t}=3.46, \mathrm{p}<.001)$, and practical considerations $(\mathrm{t}=2.46, \mathrm{p}<.05)$. In addition, there was a significant relationship with the total scale $(\mathrm{t}=6.28, \mathrm{p}<.001)$. 
Table 2. Factor loadings of the Euthanasia Attitude Scale.

\begin{tabular}{|c|c|c|c|c|}
\hline & I & 2 & 3 & 4 \\
\hline Ic & .798 & .180 & .225 & .081 \\
\hline le & .766 & .088 & .146 & .054 \\
\hline Id & .719 & .095 & .291 & -.045 \\
\hline $\mathrm{la}$ & .714 & .192 & -.091 & .218 \\
\hline $\lg$ & .700 & .121 & -.086 & .176 \\
\hline Ik & .636 & .113 & .120 & -.227 \\
\hline If & .598 & .237 & .377 & .104 \\
\hline $\mathrm{lj}$ & .595 & .144 & $.41 \mathrm{I}$ & -.096 \\
\hline $2 d$ & .563 & .333 & .256 & .152 \\
\hline $\mathrm{li}$ & .498 & .452 & .006 & -.284 \\
\hline Ih & .478 & .180 & .471 & .081 \\
\hline $3 b$ & .238 & .750 & .300 & -.282 \\
\hline $3 c$ & .274 & .732 & .356 & -.045 \\
\hline $3 a$ & .188 & .669 & -.262 & .061 \\
\hline $2 c$ & .009 & .479 & .037 & .029 \\
\hline Ib & .468 & .461 & -.082 & -.288 \\
\hline $2 a$ & .196 & .240 & .754 & -.006 \\
\hline $2 b$ & -.004 & .109 & .534 & .261 \\
\hline $3 b$ & .089 & -.174 & -.450 & .443 \\
\hline $4 a$ & .356 & .174 & .261 & .626 \\
\hline $4 b$ & .084 & .240 & -.065 & .468 \\
\hline
\end{tabular}

Bold values $p<.01$.

Table 3. Correlation coefficients between total EAS, its individual dimensions, and total ATE.

\begin{tabular}{|c|c|c|c|c|c|}
\hline & I & 2 & 3 & 4 & 5 \\
\hline Ethical considerations & .893 & & & & \\
\hline Treasuring life & $.523 * *$ & .719 & & & \\
\hline Practical considerations & $.506 * *$ & $.258 * *$ & .539 & & \\
\hline Naturalistic beliefs & $.236 * *$ & $.276 * *$ & .102 & $n / a$ & \\
\hline Total EAS & $.941 * *$ & $.709 * *$ & $.353 * *$ & $.580 * *$ & .878 \\
\hline Total ATE & $539 * *$ & $391 * *$ & $.129 *$ & $406 * *$ & $.564 * *$ \\
\hline
\end{tabular}

EAS: Euthanasia Attitude Scale; ATE: Attitude Toward Euthanasia scale.

**Spearman $\rho$ value with $\mathrm{p}<.001$ and $*_{\mathrm{p}}<005 . \mathrm{n} / \mathrm{a}=$ not applicable as it is a two-item dimension.

Cronbach's Alpha on main diagonal.

\section{Discussion}

This study aimed to research the psychometric properties of the Spanish version of the EAS questionnaire among nursing students. Validation of this tool is warranted due to the lack of existing tools for measuring the attitudes toward euthanasia in a Spanish population.

Regarding the internal consistency of the tool, this study obtained a Cronbach's alpha coefficient of .87. These results are in consonance with the findings reported in the study of the original scale, where the value obtained for the Cronbach's alpha was .84.25 This study was also in line with the study published by Tang et al. ${ }^{34}$ with a Cronbach's alpha result of .84 for the Chinese version, and the study by Aghababaei 
Table 4. Independent-sample test between dimension of EAS and professing a religion or not.

\begin{tabular}{|c|c|c|c|c|c|}
\hline & Do you profess any religion? & $\mathrm{n}$ & $M$ & SD & $\mathrm{t}$ \\
\hline \multirow[t]{2}{*}{ Ethical considerations } & No & 158 & 43.46 & 7.021 & $5.298 * *$ \\
\hline & Yes & 198 & 39.18 & 8.000 & \\
\hline \multirow[t]{2}{*}{ Treasuring life } & No & 167 & $|5.9|$ & 3.876 & $4.92^{* *}$ \\
\hline & Yes & 214 & $|4.0|$ & 3.608 & \\
\hline \multirow[t]{2}{*}{ Naturalistic belief } & No & 168 & 9.35 & 1.727 & $3.46 * *$ \\
\hline & Yes & 212 & 8.71 & 1.824 & \\
\hline \multirow{2}{*}{ Practical considerations } & No & 169 & 5.92 & 1.747 & $2.46 *$ \\
\hline & Yes & 216 & 5.47 & 1.770 & \\
\hline \multirow[t]{2}{*}{ Total EAS } & No & 149 & 74.78 & 10.62 & $6.28 * *$ \\
\hline & Yes & 188 & 67.05 & 11.67 & \\
\hline
\end{tabular}

EAS: Euthanasia Attitude Scale; SD: standard deviation. $*_{p}<.05 ; * *_{p}<.01$.

where the validity and reliability revealed a Cronbach's alpha of . 085 for the Persian version. ${ }^{35}$ The 21 items of the original scale have been maintained as, for items with lower scores, there is no statistical need to delete them as there is hardly any variation in the Cronbach's alpha.

Regarding the four-dimension factor structure suggested by Chong and Fok, ${ }^{27}$ in our study, the four dimensions have a positive correlation with the total EAS score, despite the fact that the configuration of each of the dimensions changes slightly. In the study by Tang et al., the three-factor model explains a greater percentage of the variance $(56.74 \%)$, excluding the "naturalistic beliefs" domain and introducing these items in the third domain. In this sense, the fact that the items in our model based on four factors are relocated from one domain to another has to do with the use of certain words in the translation of the same. For example, item $1 \mathrm{~b}$ has been moved to domain 3 "treasuring life" as, by using the word "merciful" it is directly related with the bible and with merciful reasons that lead a "good Christian" to take pity on any life, understanding this as a treasure as it is granted by God. Likewise, item 2 d includes the word "faith," which may be the reason it has been moved from "practical considerations," arguing that faith and practice are different instruments. These minor language variations do not affect the validity of the tool. However, it is important to remember that euthanasia is not contemplated in the Spanish law, suggesting that it is important to continue to reevaluate these results in other samples of professionals or even among the general population. Considering that beliefs of euthanasia can change and vary according to individual education and culture, it is important to remember that, in order to understand how people acquire a certain attitude, it is essential to understand how they consider, both their own death or that of others, which will also be related with their experience and/or education. An important consideration suggested at the time by Rogers 26 is that the instructions for the scale do not provide a definition of euthanasia that may help guide the respondent, especially when the test is performed in a country where euthanasia is not yet legal. In this sense, future studies should focus on the development of a definition of euthanasia, or, in our context, attempt to clarify the different concepts surrounding this process and what is currently allowed according to Spanish Law.

As stated by Virginia Henderson, a nurse must be a fundamental pillar for the patient and the family, not only during the process of illness and healing but also for the accompaniment of a good death. ${ }^{36}$ Nobody doubts that nurses play an essential role at the patient's deathbed, not just because of the affective ties that can be derived by the administrative care during the prior illness, but also because the nurse is, and will be, the one at the bedside, administering end of life care, independent of these ties. Therefore, and in the context of this national debate, it is important to explore the attitude of our nurses regarding euthanasia. In the study 
by Demedts et al. ${ }^{37}$ in Belgium, where euthanasia is legal, nurses acknowledge that they have a very important role in the entire process; however, they allude to the need for more knowledge and the elaboration of good practice guidelines. However, what about nursing students, the future health professionals? Their views are important as demographic studies show that the older population will continue to increase and therefore today's students will play a crucial role in the care of tomorrow's patients. In addition, we cannot forget how generations change behaviors, attitudes, and reasoning according to their own experiences. For this reason, we consider it is essential to understand the attitude of our nursing students and future professionals regarding such a vigorously debated subject.

Religion is considered one of the most studied variables because of its considerable influence on the opinion or attitudes toward the same, independent of which religion is followed. For Catholics, euthanasia is in direct opposition with the fifth commandment: "Thou shalt not kill." In Islam, the Quran states, in the words of Ala, "believers will not kill." Our findings have demonstrated a positive correlation between the variable "professing a religion" or not and the four dimensions of the test, as well as in the scoring of the same. This confirms previous findings, that is, the predictive capacity of the religion variable in order to tip the balance toward rejection or support for euthanasia. ${ }^{20,38-41}$ In this sense, it is important to remember that, although Spain is a secular state, the weight of the country's religious tradition is still very much instilled in the popular culture and many convictions are still present, even among those who do not profess to be Catholic.

\section{Limitations}

This study has several limitations to be considered. First, it is important to note that the EAS is a self-report tool which can be less precise for evaluating opinions. Also, this study was carried out at only one nursing faculty, therefore, further studies are required with a wider and more diverse population in order to confirm these results. Regarding the stability of the respondents' attributes, we were unable to evaluate test-retest reliability due to problems with the identification of the students who completed the questionnaire on a second occasion. Despite these limitations, the present study provides preliminary validity and evidence of reliability for the Spanish version of the EAS.

\section{Conclusion}

The Spanish adaptation of the EAS proposed in this study reveals a reliable and valid questionnaire for evaluating attitudes toward euthanasia with psychometric properties that are similar to those reported in the international literature. The Spanish version of the EAS may be effectively used as an assessment in many contexts and involving a wide range of Spanish-speaking populations. Further evidence should be gathered to explore its application in other contexts, such as professional nurses and the general population.

\section{Authors' note}

All authors meet all four criteria for authorship: (1) Substantial contributions to the conception or design of the work, the acquisition, analysis, and interpretation of data for the work; (2) drafting the work or revising it critically for important intellectual content; (3) final approval of the version to be published; and (4) agreement to be accountable for all aspects of the work in ensuring that questions related to the accuracy or integrity of any part of the work are appropriately investigated and resolved.

\section{Acknowledgements}

The authors would like to thank the students who voluntarily participated in this study. We would also like to thank the professionals who helped us with the translation of the questionnaire. 


\section{Conflict of interest}

The author(s) declared no potential conflicts of interest with respect to the research, authorship, and/or publication of this article.

\section{Funding}

The author(s) received no financial support for the research, authorship, and/or publication of this article.

\section{ORCID iDs}

Juan José Fernández-Muñoz (D) https://orcid.org/0000-0001-5519-7515

María Laura Parra-Fernandez (D) https://orcid.org/0000-0001-9681-1737

\section{References}

1. McCormack R, Clifford M and Conroy M. Attitudes of UK doctors towards euthanasia and physician-assisted suicide: a systematic literature review. Palliat Med 2012; 26(1): 23-33, https://www.redalyc.org/pdf/783/78343 122025.pdf

2. Sádaba J. Euthanasia and ethic. Rev Bioética y derecho [Journal of Bioethics and law] 2015: 237-246, https:// www.redalyc.org/pdf/783/78343122025.pdf

3. Emanuel EJ, Onwuteaka-Philipsen BD and Cohen J. Euthanasia and physician-assisted suicide-in reply. JAMA 2016; 316(15): 1600-1601, http://www.ncbi.nlm.nih.gov/pubmed/27755631

4. Cohen J, Van Landeghem P, Carpentier N, et al. Public acceptance of euthanasia in Europe: a survey study in 47 countries. Int J Public Health 2014; 59(1): 143-156.

5. Ferreira N. Latest legal and social developments in the euthanasia debate: bad moral consciences and political unrest. Med Law 2007; 26(2): 387-407, http://www.ncbi.nlm.nih.gov/pubmed/17639859

6. Cohen J, Marcoux I, Bilsen J, et al. Trends in acceptance of euthanasia among the general public in 12 European countries (1981-1999). Eur J Public Health 2006; 16(6): 663-669, http://www.ncbi.nlm.nih.gov/pubmed/ 16641157

7. Bülow H-H, Sprung CL, Baras M, et al. Are religion and religiosity important to end-of-life decisions and patient autonomy in the ICU? The Ethicatt study. Intensive Care Med 2012; 38(7): 1126-1133, http://link.springer.com/ 10.1007/s00134-012-2554-8

8. Lawrence RE and Curlin FA. Autonomy, religion and clinical decisions: findings from a national physician survey. J Med Ethics 2009; 35(4): 214-218, http://www.ncbi.nlm.nih.gov/pubmed/19332575

9. Toro-Flores R, Bravo-Agüi P, Catalán-Gómez MV, et al. Opinions of nurses regarding conscientious objection. Nurs Ethics 2017; 26: 1027-1038, http://journals.sagepub.com/doi/10.1177/0969733017731915

10. Shaw J and Downie J. Welcome to the wild, wild north: conscientious objection policies governing Canada's medical, nursing, pharmacy, and dental professions. Bioethics 2014; 28(1): 33-46, http://www.ncbi.nlm.nih.gov/ pubmed/24117541

11. Davis S, Schrader V and Belcheir MJ. Influencers of ethical beliefs and the impact on moral distress and conscientious objection. Nurs Ethics 2012; 19(6): 738-749, http://journals.sagepub.com/doi/10.1177/0969733 011423409

12. Karlsson M, Strang P and Milberg A. Attitudes toward euthanasia among Swedish medical students. Palliat Med 2007; 21(7): 615-622.

13. Verpoort C, Gastmans C, De Bal N, et al. Nurses' attitudes to euthanasia: a review of the literature. Nurs Ethics 2004; 11(4): 349-365, http://journals.sagepub.com/doi/10.1191/0969733004ne708oa

14. Terkamo-Moisio A, Gastmans C, Ryynänen O-P, et al. Finnish nurses' attitudes towards their role in the euthanasia process. Nurs Ethics 2017; 26: 700-714, http://journals.sagepub.com/doi/10.1177/0969733017720850 
15. Bendiane MK, Galinier A, Favre R, et al. French district nurses' opinions towards euthanasia, involvement in end-of-life care and nurse-patient relationship: a national phone survey. $J$ Med Ethics 2007; 33(12): 708-711.

16. Glebocka A, Gawor A and Ostrowski F. Attitudes toward euthanasia among polish physicians, nurses and people who have no professional experience with the terminally ill. Adv Exp Med Biol 2013; 788: 407-412, http://www.ncbi.nlm.nih.gov/pubmed/23836005

17. De Hert M, Van Bos L, Sweers K, et al. Attitudes of psychiatric nurses about the request for euthanasia on the basis of unbearable mental suffering (UMS). PLoS ONE 2015; 10(12): e0144749, http://www.ncbi.nlm.nih.gov/pubmed/ 26700007

18. Kranidiotis G, Ropa J, Mprianas J, et al. Attitudes towards euthanasia among Greek intensive care unit physicians and nurses. Heart Lung 2015; 44(3): 260-263, http://www.ncbi.nlm.nih.gov/pubmed/25840865

19. Woods M and Bickley Asher J. Nurses and the euthanasia debate: reflections from New Zealand. Int Nurs Rev 2015; 62(1): 13-20, http://www.ncbi.nlm.nih.gov/pubmed/25439232

20. Bendiane MK, Bouhnik A-D, Galinier A, et al. French hospital nurses' opinion about euthanasia and physician-assisted suicide: a national phone survey. J Med Ethics 2009; 35(4): 238-244, http://www.ncbi.nlm. nih.gov/pubmed/19332581

21. Oliver P, Wilson M and Malpas P. New Zealand doctors' and nurses' views on legalising assisted dying in New Zealand. N Z Med J 2017; 130(1456): 10-26, http://www.ncbi.nlm.nih.gov/pubmed/28571045

22. Ayça Ay M and Öz F. Nurses attitudes towards death, dying patients and euthanasia: a descriptive study. Nurs Ethics 2019; 26(5): 1442-1457.

23. Francke AL, Albers G, Bilsen J, et al. Nursing staff and euthanasia in the Netherlands. A nation-wide survey on attitudes and involvement in decision making and the performance of euthanasia. Patient Educ Couns 2016; 99(5): 783-789, http://www.ncbi.nlm.nih.gov/pubmed/26613667

24. Tamayo-Velázquez M-I, Simón-Lorda P and Cruz-Piqueras M. Euthanasia and physician-assisted suicide: knowledge, attitudes and experiences of nurses in Andalusia (Spain). Nurs Ethics 2012; 19(5): 677-691, http://journal s.sagepub.com/doi/10.1177/0969733011436203

25. Tordella MA and Neutens JJ. An instrument to appraise attitudes of college students toward euthanasia. J Sch Health 1979; 49(6): 351-352, http://doi.wiley.com/10.1111/j.1746-1561.1979.tb07728.x

26. Rogers JR. Assessing right to die attitudes: a conceptually guided measurement model. J Soc Issues 1996; 52(2): 63-84, https://spssi.onlinelibrary.wiley.com/doi/pdf/10.1111/j.1540-4560.1996.tb01568.x

27. Chong AM and Fok S. Attitudes toward euthanasia in Hong Kong-a comparison between physicians and the general public. Death Stud 2004; 29(1): 29-54, http://www.tandfonline.com/doi/abs/10.1080/07481180590519769

28. Wasserman J, Clair JM and Ritchey FJ. A scale to assess attitudes toward euthanasia. Omega 2005; 51(3): 229-237, http://journals.sagepub.com/doi/10.2190/FGHE-YXHX-QJEA-MTM0

29. Beaton DE, Bombardier C, Guillemin F, et al. Guidelines for the process of cross-cultural adaptation of self-report measures. Spine 2000; 25(24): 3186-3191.

30. R Development Core Team. A language and environment for statistical computing. Vienna: R Foundation for Statistical Computing, 2008, http://www.r-project.org

31. Tabachnick BG and Fidell LS. Using multivariate statistics. 2nd ed. Northridge, CA: HarperCollins, 1998, http://baunne.unne.edu.ar/documentos/EstadisticaMultivariable.pdf

32. Lorenzo-Seva U and Ferrando PJ. FACTOR: a computer program to fit the exploratory factor analysis model. Behav Res Methods 2006; 38(1): 88-91, http://www.ncbi.nlm.nih.gov/pubmed/16817517

33. Field AP. Discovering statistics using SPSS (Introducing Statistical Method series). London: SAGE, 2009.

34. Tang WK, Mak KK, Kam PMH, et al. Reliability and validity of the Euthanasia Attitude Scale (EAS) for Hong Kong medical doctors. Am J Hosp Palliat Care 2010; 27(5): 320-324.

35. Aghababaei N. Assessing attitudes toward euthanasia. Iran J Med Ethics Hist Med 2011; 5(1): 59-70, http://ijme. tums.ac.ir/browse.php?a_id=142\&sid=1\&slc_ 
36. Henderson V. The nature of nursing. Am J Nurs 1964; 64: 62-68, https://tomlinson.ua.edu/644_nurse/Readings/ henderson_nursingtheory.pdf

37. Demedts D, Roelands M, Libbrecht J, et al. The attitudes, role \& knowledge of mental health nurses towards euthanasia because of unbearable mental suffering in Belgium: a pilot study. J Psychiatr Ment Health Nurs 2018; 25(7): 400-410, http://www.ncbi.nlm.nih.gov/pubmed/29802774

38. Barry L, Hobbins A, Kelleher D, et al. Euthanasia, religiosity and the valuation of health states: results from an Irish EQ5D5L valuation study and their implications for anchor values. Health Qual Life Outcomes 2018; 16(1): 152, https://hqlo.biomedcentral.com/articles/10.1186/s12955-018-0985-9

39. Televantos A, Talias MA, Charalambous M, et al. Attitudes towards euthanasia in severely ill and dementia patients and cremation in Cyprus: a population-based survey. BMC Public Health 2013; 13: 878, http://bmcpu blichealth.biomedcentral.com/articles/10.1186/1471-2458-13-878

40. Tomlinson E and Stott J. Assisted dying in dementia: a systematic review of the international literature on the attitudes of health professionals, patients, carers and the public, and the factors associated with these. Int J Geriatr Psychiatry 2015; 30(1): 10-20, http://doi.wiley.com/10.1002/gps.4169

41. Ntantana A, Matamis D, Savvidou S, et al. The impact of healthcare professionals' personality and religious beliefs on the decisions to forego life sustaining treatments: an observational, multicentre, cross-sectional study in Greek intensive care units. BMJ Open 2017; 7(7): e013916, http://www.ncbi.nlm.nih.gov/pubmed/28733295 